\title{
DISCRIMINAÇÕES, ESTÍMULOS E OBSTÁCULOS NO CAMPO PROFISSIONAL DA MEDICINA: UM OLHAR DE GÊNERO E GERAÇÕES
}

\author{
DISCRIMINATION, INCENTIVES, AND OBSTACLES IN THE PROFESSIONAL FIELD OF MEDICINE: \\ A VISION OF GENDER AND GENERATIONS
}

Tânia Steren dos Santos ${ }^{1}$

Resumo Este artigo aborda, de forma comparativa, a realidade objetiva e representações de homens e mulheres sobre seu trabalho na medicina e as interfaces com a esfera doméstica. São analisados discriminações, estímulos e obstáculos para a carreira profissional, na perspectiva de gênero e gerações. Os dados foram coletados no Hospital de Clínicas de Porto Alegre (HCPA), integrando técnicas quantitativas e qualitativas. Os resultados indicam que, para explicar os fatores de estímulo para a carreira, as mulheres parecem voltar-se mais para elementos da vida privada enquanto os homens enfatizam mais alguns fatores externos. Ambos salientam a importância de ter um 'modelo' de profissional tomado como ideal para o exercício profissional e um ambiente acadêmico positivo, com apoio institucional e bom relacionamento com os colegas de trabalho. Entre os obstáculos: excesso de trabalho, falta de tempo e dificuldades financeiras, observando-se diferenciações de gênero quanto à vida familiar e problemas pessoais. Foram salientadas as 'vantagens comparativas' das mulheres no desempenho das suas atividades. Este estudo pode contribuir para a implementação de ações positivas para a melhoria das condições do trabalho profissional e da equidade de gênero, tanto na esfera pública quanto na privada.

Palavras-chave gênero, carreira profissional, discriminações.
Abstract This article discusses, in a comparative way, the objective reality and representations of men and women concerning their work in medicine and the interfaces with the domestic sphere. Discrimination, incentives, and obstacles in careers are analyzed from the perspective of gender and generations. Data was collected at the Hospital de Clínicas de Porto Alegre (HCPA), integrating quantitative and qualitative techniques. The results indicate that in order to explain career incentive factors, women seem to give more importance to private life elements while men put more emphasis on external factors. Both stress the importance of having a 'model' professional as ideal for professional practice and a positive academic environment with institutional support and good relationships with coworkers. Among the obstacles are overwork, lack of time, and financial difficulties, observing that there are differences of gender in regards to family life and personal problems. Women's 'comparative advantages' were highlighted in carrying out their activities. This study may contribute to the implementation of positive actions to improve the conditions of work life and gender equity, in both the public and private spheres.

Keywords gender, career, discrimination. 


\section{Introdução}

Neste artigo são analisados diversos fatores que podem explicar a melhor progressão na carreira profissional na medicina, assim como aqueles que se constituem em entraves, na perspectiva de gênero e geracional. Em depoimentos, médicos e médicas enfatizaram diversos aspectos que, na opinião deles, podem beneficiar ou prejudicar a sua trajetória profissional. Ambos os gêneros apresentam um perfil diferenciado, embora ocorra também uma confluência de perspectiva em relação a alguns fatores explicativos.

A carreira profissional apresenta uma determinada cronologia de etapas, que começa com uma iniciação no mercado de trabalho e, após diversas fases, nas quais se pode identificar uma trajetória linear ou com algumas interrupções (principalmente no caso das mulheres), entra num período de desaceleração e paralisação das atividades. ${ }^{2} \mathrm{Na}$ maioria das vezes, as expectativas de sucesso determinam as características da trajetória de cada profissional, onde o tipo de personalidade e o estabelecimento de objetivos influenciam conquistas e realizações. No entanto, cabe lembrar que o crescimento profissional, a competência e o reconhecimento são moldados pelas condições concretas e objetivas de vida dos sujeitos, mais do que por determinantes relacionados à vontade e à ação individual.

As relações que os sujeitos estabelecem com a realidade material e entre si são moldadas pela sua situação concreta nas dimensões objetivas e subjetivas, ou seja, são determinadas pelas estruturas sociais e representações simbólicas da sociedade na qual estão inseridos.

A realidade vivenciada e as representações são aqui objetos privilegiados, adotando-se a seguinte definição de Saffioti desta última categoria, explicando que ela não se confunde com a experiência, com a vivência: “A representação é o pensar-sentir a vivência. Tem lugar segundo uma base material, que nutre o nível simbólico e por ele é alimentada. Na realidade concreta não se podem separar o material e o simbólico: um é constitutivo do outro" (Saffioti, 1992, p. 209). A autora enfatiza a perspectiva dialética, ao considerar que a representação "é a subjetivação da objetividade que, na condição de mola propulsora da ação, volta para o mundo da objetividade" (Saffioti, 2000, p. 74).

O meio ambiente familiar e social representa o locus no qual se estabelecem as interações entre os diversos agentes e onde as suas trajetórias são cotidianamente construídas. Nesse sentido, as suas representações são determinadas pelas relações objetivas e, ao mesmo tempo, exercem influência em comportamentos e estruturações da vida pessoal e profissional.

O gênero continua sendo um fator de discriminação e preconceito no meio ambiente de trabalho, especialmente no que se refere ao acesso das mulheres aos postos mais valorizados e cargos de comando. ${ }^{3}$ Apesar desta 
dificuldade, a situação das mulheres tem apresentado transformações significativas nos últimos anos, observando-se maior equidade e valorização de algumas características femininas. 'Deficiências', que anteriormente eram vistas como empecilhos, passam a ser consideradas como 'vantagens comparativas' positivas no campo profissional. Na medida em que se identificam preconceitos e se valorizam as diferentes capacidades de homens e mulheres, independentemente de estigmas e rotulações, se ampliam as possibilidades de instituir relações sociais mais humanas e equitativas.

O levantamento de dados foi realizado no Hospital de Clínicas de Porto Alegre (HCPA), a partir da combinação de técnicas quantitativas e qualitativas. Foi pesquisada uma amostra de médicos, da qual, de forma equilibrada, fazem parte profissionais de ambos os gêneros, de diversas gerações e das três categorias de vínculo de trabalho: professores da Faculdade de Medicina (Famed) da Universidade Federal do Rio Grande do Sul, médicos contratados4 e médicos residentes. O estudo qualitativo foi realizado a partir de uma amostra diversificada de médicos e médicas, também constituída de situações diferenciadas em termos de categorias funcionais, gênero e idade. ${ }^{5}$

\section{Discriminações no campo profissional}

Procurou-se indagar inicialmente a respeito das representações dos médicos e médicas que atuam no HCPA sobre a existência ou não de discriminações na sua vivência profissional cotidiana.

Tabela 1

\begin{tabular}{|c|c|c|c|c|c|}
\hline & & \multicolumn{3}{|c|}{ Discriminações e obstáculos } & \multirow[b]{2}{*}{ Total } \\
\hline & & Nunca & Ocasionalmente & Frequentemente & \\
\hline \multirow{3}{*}{ Gênero } & Homens & $31(34 \%)$ & $50(54 \%)$ & $11(12 \%)$ & $92(100 \%)$ \\
\hline & Mulheres & $42(48 \%)$ & $40(45 \%)$ & $6(7 \%)$ & $88(100 \%)$ \\
\hline & Total & $73(41 \%)$ & $90(50 \%)$ & $17(9 \%)$ & 180 (100\%) \\
\hline
\end{tabular}

Fonte: A autora. 
Os dados revelam que as mulheres apresentam percentagens um pouco mais elevadas que os homens no sentimento de existência de discriminações que se manifestam ao desempenharem o seu trabalho profissional. Observando-se a categoria 'ocasionalmente' e 'frequentemente', a proporção de mulheres é superior à dos homens, entretanto o teste de associação não é significativo: $\chi^{2} 4,152 ;$ gl 2; p-value $=0,125$. Como os dados da tabela são muito gerais, procurou-se também indagar, em maior detalhe, quais são as discriminações mais frequentes percebidas por homens e mulheres, incluindo outra pergunta no questionário sobre tipos de discriminação. Os resultados indicam que a discriminação por 'sexo' é a que teve percentagem maior entre as mulheres. Segue-se a discriminação por 'idade' e 'por não ser muito conhecido', em ordem decrescente de importância, em ambos os gêneros. 6

Na pesquisa qualitativa, depoimentos de vários médicos e médicas indicam outros fatores de discriminação e, mesmo que suas respostas não sejam estatisticamente representativas, elas oferecem uma interessante contribuição, na medida em que possibilitam visualizar alguns aspectos conflitivos da sua realidade cotidiana. Entre os principais fatores assinalados estão os seguintes: manifestações de inveja pelo sucesso dos outros; não se sentir reconhecido e valorizado como profissional por parte daqueles que ocupam espaços importantes nas instâncias de poder; discriminações pela nacionalidade, pela orientação política ou por ter vínculo com o hospital como contratado e não como professor da Famed. De todas as diferentes formas de discriminação identificadas, serão analisadas, em maior profundidade, as determinadas pelo gênero e pela idade.

As discriminações de gênero no trabalho são produto da materialização de estereótipos quanto aos papéis masculinos e femininos, observando-se nesses sistemas classificatórios a atribuição de um status subalterno às atividades desempenhadas por mulheres. Maria Jesús Izquierdo afirma que existem desigualdades de gênero incorporadas nas próprias atividades consideradas como específicas de mulheres ou de homens, independentemente do sexo de quem as executa:

Manifestaciones de la desigualdad estructural de género son el hecho de que el nivel redistributivo, formativo, de prestigio y/o de poder para las actividades femeninas es inferior al que se le otorga a las actividades masculinas, al margen de que quienes las desarrollan sean hembras o machos (Izquierdo, 1998, p. 51).

A sociedade produz diversas formas de catalogação e hierarquização para designar as características da atuação masculina e feminina. Os mecanismos de reprodução das relações de gênero moldam os papéis e os comportamentos considerados adequados a homens e mulheres. Conforme Bourdieu (1999), a "dominação masculina" imprime traços nos corpos e habitus das 
pessoas e este se materializa nos diversos campos da vida social.7 No entanto, é necessário destacar que as características predominantes do comportamento e representações de cada gênero estão mudando de acordo com novas pautas da socialização presentes nas novas gerações, criando padrões mais igualitários entre homens e mulheres na nossa sociedade.

Na medicina, o processo de feminização tem provocado modificações nas representações sobre as mulheres médicas e alguns estereótipos de gênero parecem estar sendo superados. Desde a época em que as primeiras mulheres começaram a estudar nas faculdades de medicina e iniciaram sua inserção no mercado de trabalho, algumas transformações importantes têm ocorrido. O sistema de ingresso no curso, através de vestibular, tem sido um fator decisivo na equidade de gênero na profissão, pois antigamente, quando existia a prova escrita e oral, entravam somente uma ou duas mulheres por turma. É interessante ampliar o olhar sobre períodos anteriores para se ter uma perspectiva mais abrangente da situação da mulher na medicina, das discriminações mais intensas em anos anteriores e das mudanças que vêm ocorrendo.

No que se refere à relação entre colegas de faculdade e com os professores, a leitura dos relatos permite identificar três gerações de médicos e médicas, com uma experiência diferente quanto às relações sociais no ambiente acadêmico: uma primeira geração, que atualmente é composta de médicos de mais idade, na faixa acima dos 60 anos; uma geração intermediária, formada hoje por pessoas na faixa dos 40 a 50 anos; e uma geração mais jovem de profissionais.

Nos relatos da primeira geração percebe-se que antigamente as relações eram mais formais entre professores e alunos e entre colegas do sexo feminino e masculino. Uma doutora, que hoje está na faixa dos 70 anos, e foi uma das pioneiras na faculdade, menciona certo distanciamento com os professores: “Com os professores tinha uma distância quilométrica! Mas, com os colegas, não tinha muita diferença; eles nos respeitavam e eu era mais retraída, e sempre nós cuidávamos de como gostaríamos de ser tratadas, não tinha aquela intimidade" (Sexo feminino, viúva, sem filhos, 70 anos). As mulheres não conviviam demasiadamente com os estudantes fora da universidade: “Os rapazes faziam programas entre eles, de sair, de ir a festinhas, mas o relacionamento era bastante bom e bastante jovial" (Sexo feminino, solteira, 62 anos).

No depoimento do um dos médicos de mais idade, também existe uma referência à falta de aproximação que existia entre alunos e professores: “Ah! Os professores antigamente tinham uma posição [superior]. Não era qualquer professor que ajudava. Hoje eles democratizaram a coisa, antes havia mais distância entre professores e alunos. Era tudo mais bruto! Hoje tudo é mais delicado" (Sexo masculino, viúvo, sete filhos, 81 anos). 
De acordo com os relatos, não era permitido às mulheres fazerem plantão e estágio devido aos inúmeros preconceitos existentes. Uma médica afirma que as mulheres eram mais protegidas pelos professores e pela família e que "seu comportamento era mais vigiado". A entrevistada refere que o pai costumava ir até a saída do Pronto Socorro para procurá-la e que as enfermeiras que ali trabalhavam eram olhadas com preconceito. Explica que existia entre as médicas um extremo cuidado de não provocar comentários e pequenas intrigas e que as relações sociais eram mais formais no ambiente de trabalho.

A questão da mencionada vigilância lembra algumas considerações de Michel Foucault, na sua obra Vigiar e punir (Foucault, 1977), sobre a constante observação a que são submetidos os dominados, com o objetivo de controlar melhor sua subjetividade, redes de sociabilidades e formas de agir. O seguinte depoimento, ademais, confirma a existência de forte discriminação de gênero no decorrer da trajetória profissional de uma médica da primeira geração:

Ao longo da minha carreira, quando você não sofria assédio sexual, o professor te chamava de 'minha filha'! E eu respondia: 'Eu não sou sua filha, sou sua colega!' [A relação] ou era paternal ou havia assédio sexual. Não havia a preparação psicológica dos colegas mais velhos e mais titulados para encarar uma mulher como colega! É claro que se eu tivesse entrado na medicina vinte anos depois teria sido tudo muito mais fácil! (Sexo feminino, solteira, 62 anos).

Na segunda geração (faixa dos 40 a 50 anos), nota-se uma aproximação maior entre colegas, e entre alunos e professores, embora ainda persistam alguns preconceitos em relação à mulher. Fora alguns casos isolados, existia boa interação entre ambos os gêneros e em alguns depoimentos é mencionada uma atitude de apoio e proteção. No entanto, a análise do discurso põe em evidência também a existência de alguns preconceitos:

A gente era meio protegida pelos colegas em situações difíceis. Os meus amigos foram muito solidários, mas a gente percebia que alguns colegas tinham certa restrição às mulheres, achavam que as mulheres não teriam condições de desenvolvimento (Sexo feminino, casada, três filhos, 54 anos).

No testemunho de uma médica, na faixa dos 40 anos, observa-se que a dominação masculina às vezes é exercida de forma inconteste, gerando grande constrangimento nesta mulher colocada em posição subalterna:

Tive alguns exemplos mais trogloditas, especialmente nas áreas básicas. Tive um professor de anatomia que não gostava de mulheres. O discurso dele era completamente antimulher. Eu era aluna do colégio Aplicação, sempre tinha ido bem, de 
repente, entrei na anatomia, e eram provas orais, e fico vermelha quando tenho que falar, é uma coisa insuportável. Eu ia falar no meio da aula e ficava toda vermelha. Então, na prova oral, comecei a falar e a ficar vermelha. Ele disse: 'Tu estás vermelha!'. Fiquei um pimentão vermelho e comecei a gaguejar! Me detonei completamente!! Ele então começou a falar como achava que pessoas da minha idade não tinham maturidade para fazer medicina e que as mulheres eram frágeis emocionalmente. Ele dizia: 'Olha, uma coisa tão simples, como mostrar conhecimento, e tu estás vermelha, tremendo e gaguejando', e aí eu afundei completamente! Tirei seis naquela prova e foi muito estressante. Para a segunda prova, eu me matei de estudar! Passei todo o tempo olhando pro sapato dele, era a coisa mais esquizóide! A prova inteira, ele perguntava, e eu respondia olhando pro sapato dele, não olhei pra cara dele [risos] e ele passou o tempo todo perguntando, perguntando e eu fui respondendo, respondendo e eu não olhei pra cara dele. Aí, ele terminou e disse: 'Tá, tu já terminaste, tirou dez, pode olhar pra minha cara!' E eu disse: 'Não quero olhar pra sua cara!' (Sexo feminino, casada, um filho, 41 anos).

No trecho que se segue observa-se outro exemplo de discriminação de gênero que ocorreu entre os próprios colegas na área de cirurgia e a surpreendente postura desta médica:

Eu comecei a instrumentar pelo quarto ano da faculdade, fazia instrumentação cirúrgica sempre que podia, no quinto ano eu já estava auxiliando na cirurgia e no sexto já estava operando, mas eles não me deixavam crescer no grupo! Eram seis ou oito médicos e lembro que eu tinha terminado a Residência e um dia fui, ao fim da tarde, no consultório, uma cirurgia ia ser feita, era uma cirurgia de porte maior, era de um paciente privado, e estavam discutindo coisas. Eu tirei a história do paciente e tudo mais, e quando eles começaram a definir os procedimentos da cirurgia para combinar com a família, eles me disseram: 'Traz um cafezinho para nós', aí peguei umas seis, oito xicrinhas de café e atirei no meio do tapete e nunca mais voltei! Meu grande mestre estava ali, mas ele me ensinou muito, e continuei amiga dele (Sexo feminino, casada, sem filhos, 47 anos).

A atitude aqui adotada demonstra que a entrevistada quis preservar a autoestima como profissional e como mulher, buscando dignidade e respeito. Ela relata que, depois desse episódio, continuou tendo contato com aqueles profissionais e que, "num outro momento, eu voltei, mas não mais como a 'Aninha' [nome fictício]; voltei como colega e hoje até dinheiro eu empresto para eles! A coisa mudou!"

$\mathrm{Na}$ terceira geração (faixas dos 20 e 30 anos) verificam-se avanços nas relações de gênero na medicina. A presença feminina na profissão tem alterado a imagem da mulher tradicional. Nas novas gerações existe um convívio maior entre colegas e verifica-se a superação de alguns estereótipos sobre as 
mulheres. Diversos trechos de entrevistas evidenciaram a existência de experiências mais igualitárias: "Durante a faculdade nem uma vez tive problemas pelo fato de ser mulher e nem em relação aos meus colegas, eu fui até líder da minha turma a faculdade inteira, organizava reuniões, formaturas, eu acho até que as mulheres trabalhavam mais que os homens" (Sexo feminino, solteira, 28 anos). Um médico também conta que: "Era muito boa a convivência, estudávamos juntos, fazíamos muita festa juntos, era uma turma boa e unida. Até hoje a gente encaminha, com uma frequência grande, paciente um para o outro" (Sexo masculino, casado, um filho, 38 anos).

No imaginário social surge, gradativamente, uma nova concepção das relações de gênero. Um jovem médico sinaliza os novos tempos na medicina, onde as relações entre homens e mulheres se tornam cada vez mais equitativas: "A gente dividia por igual na época de Residência, plantão, horário de dormir à noite, não interessava se era homem, se era mulher, não tinha preferência, 'é mulher, então não vai fazer plantão!' No Natal era tudo igual" (Sexo masculino, casado, um filho, 38 anos). Entretanto, é necessário salientar que continuam existindo algumas dificuldades: as mulheres, geralmente, precisam de maiores esforços para 'provar' a sua competência, se comparado com os homens.

Em relação à discriminação por idade, os dados da pesquisa no HCPA indicam que médicos e médicas muito jovens ou mais velhos enfrentam alguns preconceitos. Ser jovem demais pode ser um problema no exercício profissional devido à insegurança e falta de confiança que isto pode gerar nos pacientes, nos seus familiares e até em colegas mais experientes. Este tipo de discriminação apareceu na narrativa de uma médica em início de carreira:

No primeiro ano, nas aulas de anatomia, alguns professores mais velhos ficavam ironizando. Depois, na Residência, fui discriminada na ortopedia, frontalmente. Numa forma de brincar, eu me vestia mais como senhora, de salto alto, porque queria parecer de mais idade, aí eu vim de sapato de camurça preta, meia preta, toda arrumada, foi o primeiro dia de estágio e entrei na sala do gesso e eles riam que se matavam, mandaram eu abrir um gesso de uma perna inteira e achavam que eu ia desistir, mas abri o gesso, estraguei o sapato, estraguei a saia, estraguei tudo! (risos) Eu estava de avental, mas com uma roupa preta por baixo, toda chiquérrima e destruí tudo com o gesso, mas não deixei de fazer meu trabalho. Depois eu me acostumei a vir com sapatos confortáveis e a trabalhar de uma forma mais confortável, mas no inicio eu queria parecer mais velha para impor respeito. Durante a cirurgia, logo que me formei, muitas vezes eu vinha aqui na secretaria do bloco para falar com os familiares (...) quando a pessoa já estava operada e dizer que estava tudo bem e não foi nem uma nem duas, foram muitas vezes que ouvi: 'Sra. Enfermeirinha, fique tranquila, que aquele 'doutor' de óculos já me informou que está tudo bem, quando quem tinha operado era eu! Sempre passei por 
enfermeira, enfermeirinha, doutorinha depois. Agora acho que já estou velha, já me chamam 'doutora ou já se acostumaram que tem mulher trabalhando (Sexo feminino, casada, sem filhos, 47 anos).

Paradoxalmente, o fato de ser um profissional de mais idade também pode provocar algum tipo de discriminação ou obstáculo. Veja-se o desabafo de uma médica, na faixa dos 50 anos, que tem sentido alguns preconceitos nos últimos tempos pelo fato de ter mais idade: "Eu tive sorte de estar em um departamento onde havia muita solidariedade, e continua havendo, mas, de uma década para cá, a sensação que eu tenho é que os mais jovens vêm atropelando os mais velhos" (Sexo feminino, casada, três filhos, 54 anos).

É preciso atentar, porém, que ser um profissional mais velho pode ser visto também como um fator positivo. Ocorre que muitas pessoas valorizam mais a figura daquele que transmite uma imagem de maior experiência: “E, por outro lado, eu vejo que quem é mais jovem fica inseguro. Eu acho que, sendo mais velha, tu podes passar tua própria experiência também frente à dor do paciente, as angústias, as dúvidas" (sexo feminino, 37 anos, sem filhos). ${ }^{8}$

\section{Estímulos para a carreira profissional}

O Quadro 1 refere-se aos estímulos para a carreira profissional. Foram destacados diversos exemplos de depoimentos femininos e masculinos. Procurouse identificar os elementos que compõem as representações peculiares a cada um dos gêneros, sem perder de vista também os fatores comuns, de maior destaque, mencionados por homens e mulheres durante as entrevistas.

Quadro 1

\begin{tabular}{cc}
\hline Opinião sobre discriminações e obstáculos no trabalho profissional, segundo sexo \\
\hline Mulheres & Homens \\
\hline $\begin{array}{c}\text { Incentivo da família, apoio do cônjuge } \\
\text { Tipo de personalidade, dedicação }\end{array}$ & Familiares médicos no mercado de trabalho \\
Concursos públicos & Consciência social e política \\
Importância dos elogios & Ambos os gêneros \\
\hline Tomar um profissional competente como 'modelo' a ser seguido \\
Influência positiva do ambiente acadêmico \\
Apoio de instituições financiadoras de projetos de pesquisa
\end{tabular}




\section{Os fatores de estímulo mencionados pelas mulheres}

Quanto ao fator 'Incentivo da família, apoio do cônjuge', alguns entrevistados fizeram referência à família como fator positivo ao crescimento profissional. Foi frequente no discurso das mulheres as referências ao apoio dos cônjuges, enquanto que nenhum homem, durante as entrevistas, mencionou a esposa como sendo um estímulo na sua vida profissional, mesmo que o seja:

Acho que é muito importante para esta profissão, que exige uma dedicação muito grande. A minha grande família, pai, mãe, irmãos, sempre me deram o apoio que eu precisava e minha pequena família, porque eu tive e tenho bastante apoio por parte do meu marido, inclusive no sentido de cuidar das crianças para eu poder sair para atender pacientes. $\mathrm{Na}$ época em que fiz mestrado, ele tirava as filhas de casa, sábado e domingo, para eu poder ficar estudando e me apoiou em todas as decisões de ser chefe disso, chefe daquilo, aumentar carga de trabalho (Sexo feminino, casada, dois filhos, 50 anos).

Este relato é muito importante, pois indica que a vida familiar não se constitui necessariamente num obstáculo para a carreira profissional. Ela pode oferecer elementos favoráveis em termos de resolução das necessidades afetivas e emocionais e de infraestrutura de apoio às atividades extralar dos profissionais.

Em relação ao 'tipo de personalidade, dedicação', uma entrevistada assim se expressou:

Eu não sou de 'vai fazer isso para mim!' Não! Eu vou lá e faço, e gosto! Eu tenho a impressão de que não vai ser bem feito e eu mexo com o meu orientador: ‘Eu estou no lugar certo, que é dentro de um laboratório', porque sou meio obsessiva, quero tudo certinho, tudo bonitinho; se dentro de um laboratório tu tens que pegar meia grama, é meia grama, não é 0,4! (Sexo feminino, solteira, 37 anos).

As falas a seguir assinalam a importância dos 'concursos públicos' no referencial simbólico das mulheres:

Acho que é uma das coisas que eu sempre dei muito valor, todos os cargos eu passei sempre por concurso público e isso foi um grande incentivo! Eu nunca gostei, eu detesto pensar que poderia estar devendo favor para alguém (Sexo feminino, casada, dois filhos, 42 anos).

Há muito, muito mais excluídos do que as mulheres: todos os pobres, os negros, os índios! Eu acho que a ordem não sei qual é, mas acho que a gente até conquistou determinados espaços. Eu agradeço: que bom que tem concurso público! Meu 
único pistolão era o feijão da minha mãe; então, que bom que tem concurso porque ali te iguala. Eu não sei o que seria da minha vida sem concurso! Eu nunca consegui nada sem concurso! (Sexo feminino, casada, um filho, 41 anos).

Deve ser assinalado que somente no discurso feminino apareceram referências à importância que têm os concursos públicos para preenchimento de cargos, pois nenhum homem abordou espontaneamente, durante a entrevista, esta questão. As mulheres percebem que este é um canal que abre espaço para sua melhor inserção no mercado de trabalho, na medida em que pode reduzir manifestações de discriminações e preconceitos de gênero. As médicas consideraram que esse é um fator fundamental para uma maior equidade no campo profissional.

A seguir, um depoimento que salienta a 'importância dos elogios':

Eu também fico muito gratificada, como fiquei alguns dias atrás, porque uma pessoa veio me dizer: 'Olha, eu vou te contar, uma pessoa que não gostava de ti no início de tua gestão, te elogiou, disse que tu és uma pessoa muito firme, que o departamento melhorou muito e que era uma pessoa que não gostava de ti e agora é um admirador!' Eu não preciso saber quem é. Acho que esse tipo de estímulo é muito bom, pois a pessoa precisa saber que está fazendo a coisa certa! E o outro dia também uma colega me parou no meio do corredor e me pediu para me dar um abraço! Mas que coisa boa ganhar um abraço a essa hora da manhã! E ela me disse: 'Eu quero te dar um abraço porque às vezes a gente não diz para as pessoas o quanto a gente gosta'. E ela disse: 'Eu gosto muito de ti e acho que tu estás fazendo um trabalho muito bom'. Agora uma pessoa que não gosta de ti te elogiar! Isto dá vontade de escrever num papel, emoldurar e pendurar na sala! E eu fui homenageada pelos alunos! Acho que mesmo que eu tivesse muita adversidade, essas três coisas iam me impulsionar para frente durante uns dez anos! As pessoas têm medo de parecerem piegas e elas ficam segurando os elogios e não sabem como é importante receber uns de vez em quando! (Sexo feminino, casada, dois filhos, 50 anos).

\section{Os fatores de estímulo mencionados pelos homens}

Nos depoimentos masculinos, o 'encaminhamento de pacientes' é considerado um estímulo importante para a carreira:

Como se está numa época de crise, ninguém pede trabalho para o outro, cada um se diferencia no seu espaço, na sua clínica ou no seu emprego, com mecanismos de encaminhamento, de captação de pacientes (Sexo masculino, casado, dois filhos, 58 anos). 
Os 'familiares médicos no mercado de trabalho' se constituem em fatores de estímulo:

Meu pai era médico, meu avô era médico, era professor da faculdade. Eu, na verdade, trabalhei com eles muito mais para aprender, para me tornar conhecido, para ter experiências que propriamente por remuneração. Meu primeiro impulso era trabalhar, abrir frentes (Sexo masculino, divorciado, dois filhos que não residem com ele, 53 anos).

Quanto à 'consciência social e política', o seguinte depoimento de um médico é elucidativo:

Acho que uma coisa que tem ajudado muito a minha carreira é eu ter tido contato com uma parte da sociedade que os meus colegas não têm. Muitos não entendem a situação de carência de muitos pacientes. Acho que a vivência política ajuda muito também. Na medicina tem que ter essa visão muito aberta de sociedade, de verbas destinadas à área da saúde ou não, e de planejamento, até para mudar o estado da saúde no país, tem que se investir mais em saúde ambulatorial e menos em saúde hospitalar (Sexo masculino, solteiro, um filho, 29 anos).

No discurso masculino aparecem elementos da competição por espaço e oportunidades de trabalho, mas ao mesmo tempo são mencionadas formas solidárias de colaboração entre os colegas de profissão. No das mulheres, a indicação de familiares médicos como fator de estímulo não foi frequente, nem a referência a aspectos sociopolíticos. No entanto, existe atualmente uma tendência a que as mulheres se insiram em maior número na área da saúde pública, medicina comunitária, epidemiologia e outros espaços voltados para a problemática da relação medicina-sociedade.

\section{Os estímulos no discurso de ambos os gêneros}

Um aspecto interessante identificado na pesquisa é a relevância que adquire, na trajetória dos médicos e médicas, principalmente no período de formação, a figura de um profissional que trabalha com competência e ética, o qual é tomado como modelo ideal a ser seguido. Uma médica explica: "Profissionalmente, eu as admirava e via como é que elas lidavam com as suas coisas pessoais e profissionais. Eu acho que o modelo, para nós, na medicina, se constitui num referencial importante para a vida" (Sexo feminino, casada, três filhos, 54 anos). Vários médicos também fizeram referência à importância do 'mestre-guia' na sua qualificação, formação ética e trajetória profissional. 
Alguns entrevistados, de ambos os gêneros, também fizeram referências à influência positiva do ambiente acadêmico, pois este propicia maior incentivo às pesquisas, publicações e participação em eventos. Salientam, ademais, que o contato com professores qualificados possibilita uma boa formação. A notoriedade institucional é destaque no seguinte depoimento: "A faculdade que eu fiz, a UFRGS, acho que ajudou muito e ajuda para o futuro profissional, porque se tu dizes que estudou na UFRGS, o pessoal te trata diferente. Às vezes tu passas numa seleção só por isso" (Sexo masculino, solteiro, um filho, 29 anos).

Nessa fala observa-se um exemplo nítido de posse de um capital cultural e científico, como definido por Bourdieu (1983). A posse destes capitais possibilita compreender o processo de aquisição de conhecimentos e de valorização social das habilidades.

O capital cultural se refere ao capital escolar (diploma etc.) e ao capital herdado da família, que pode ser tanto cultural quanto econômico. Barbosa considera que o capital cultural estabelece um "princípio de hierarquização oposto, mas dialeticamente integrado ao capital econômico e ao capital social (...)" e explica que o capital cultural "é o principal eixo de estruturação do campo das profissões, define as condições de produção (através da escola), de distribuição (através da atuação organizada no mercado) e de controle (através das diversas formas de hierarquização, organização e representação dos profissionais" (Barbosa, 1993, p. 24).

O campo científico interessa mais diretamente aos objetivos deste estudo. É o campo que configura o espaço principal no qual a categoria profissional médica realiza sua prática cotidiana (como criadores, divulgadores ou na aplicação prática do conhecimento científico gerado nos institutos e centros de investigação). Considera Bourdieu que é pela posse do capital científico que os agentes procuram o reconhecimento da sua competência e autoridade. No seu referencial, estes conceitos adquirem uma posição central para explicar a configuração das profissões. Caracteriza este campo da seguinte forma:

O campo científico, enquanto sistema de relações objetivas entre posições adquiridas (em lutas anteriores), é o lugar, o espaço de jogo de uma luta concorrencial. O que está em jogo especificamente nessa luta é o monopólio de autoridade científica definida, de maneira inseparável, como capacidade técnica e poder social; ou, se quisermos, o monopólio da competência científica, compreendida enquanto capacidade de falar e de agir legitimamente (isto é, de maneira autorizada e com autoridade), que é socialmente outorgada a um agente determinado (Bourdieu, 1983, p. 122).

Bourdieu salienta também que todas as práticas dos agentes nesse campo estão orientadas no sentido da autoridade científica, através da busca constante 
de "prestígio, reconhecimento e celebridade", onde a ostentação de títulos e distinções científicas adquire um papel fundamental. Menciona ademais que "os julgamentos sobre a capacidade científica de um estudante ou de um pesquisador estão sempre contaminados, no transcurso de sua carreira, pelo conhecimento da posição que ele ocupa nas hierarquias instituídas (as Grandes Escolas, na França, ou as universidades, por exemplo, nos Estados Unidos)" (Bourdieu, 1983, p. 124). Em obra mais recente, intitulada Os usos sociais da ciência: por uma sociologia clinica do campo científico (2004), o autor trata com maior profundidade do capital científico, apresentando algumas proposições normativas para favorecer o desenvolvimento de 'melhores pesquisas' e 'melhores pesquisadores'.

Em alguns relatos dos entrevistados também é mencionado o incentivo que representa para a carreira a convivência cotidiana de alunos e professores no ambiente acadêmico. Indicam, como fator de estímulo, o fato de trabalhar em espaços onde exista uma boa integração entre as pessoas, permitindo-lhes atuar com autonomia e respeito. Uma médica comenta: "O que tem aberto para mim, primeiro, é meu próprio desempenho pessoal e eu acho que tenho um bom relacionamento com as pessoas, eu não tenho muitas discórdias, porque também neste campo não sei se você ainda não notou que têm um monte de gente que odeia outro monte de gente!" (Sexo feminino, casada, um filho, 39 anos). Observe-se que nestas últimas palavras aparece a existência de conflitos entre os profissionais como um fator negativo e isto explica que seja enfatizada, por homens e mulheres, a importância de estabelecer um bom relacionamento entre colegas de trabalho.

Diversas publicações são dedicadas à importância de ter 'inteligência emocional' no campo das relações de trabalho. ${ }^{9}$ Numa pesquisa realizada no Rio de Janeiro sobre esta questão, a autora menciona diversos fatores que afetam o desempenho individual no trabalho: inteligência, experiência e conhecimento, personalidade e valores (Valle, 2006).

Outra questão indicada como fator de estímulo na carreira, considerando-se o conjunto dos entrevistados, sem diferença de gênero, diz respeito à importância do apoio de instituições que oferecem verbas para pesquisa e qualificação como, por exemplo, a Capes e o CNPq.

\section{Obstáculos para a carreira profissional}

O Quadro 2 mostra quais são os obstáculos para a carreira profissional, indicado por médicos e médicas, comparativamente. Alguns fatores foram mencionados por ambos os gêneros, como pode ser observado a seguir. 
Quadro 2

\begin{tabular}{cc}
\hline Obstáculos para a carreira profissional segundo sexo & Homens \\
\hline Mulheres & Vida familiar \\
Excesso de encargos domésticos & Referência à paternidade \\
Referência à maternidade, ao ciclo vital & Problemas pessoais, saúde emocional \\
Problemas de saúde física & Ambos os gêneros \\
Preservação da intimidade e/ou imagem & \\
\hline & Falta de tempo, excesso de trabalho \\
&
\end{tabular}

\section{Os obstáculos mencionados pelas mulheres}

No caso das mulheres, as referências à maternidade e às tarefas domésticas, como motivo de 'atraso' na carreira, são muito frequentes, mesmo naquelas que têm a colaboração de outros membros da família ou de empregada doméstica, pois às vezes estas faltam, abandonam o emprego ou estão em período de férias. Deve-se levar em consideração, ademais, que existem certas responsabilidades ligadas ao lar que são mais difíceis de serem delegadas. Uma médica, ao ser indagada a respeito de alguns fatores que sentia como obstáculos, responde: “A minha saúde e as responsabilidades domésticas, se a infraestrutura funcionasse!" (Sexo feminino, casada, dois filhos, 54 anos).

As mulheres enfatizam o 'excesso de encargos domésticos':

Quando o homem chega em casa, de uma forma geral, está com tudo estruturado; a mulher tem que organizar a vida doméstica. Eu trabalho oito, nove horas e depois tenho que ir ao supermercado. Tenho uma ótima empregada doméstica, que fica o dia inteiro, mas tenho que comprar as coisas para ela trabalhar, para ela cozinhar e meu marido não faz nada em casa, nada! Se eu tivesse filho, não poderia trabalhar como trabalho, certamente, imagina fazer plantão! Isso aí acho que é unânime, universal, a mulher não pode trabalhar no ritmo que um homem trabalha se ela tiver filhos, se ela quisesse criar os filhos direito! Se ela quiser parir para os outros criarem, até dá, mas se ela for mãe, se for uma dona de casa e se preocupar com a administração doméstica, fica muito difícil! (Sexo feminino, casada, sem filhos, 47 anos).

Nos depoimentos femininos foram frequentes a 'referência à maternidade': 
Eu acho que isso segura um pouco o trabalho da mulher. A gente vê que os homens são mais 'livres' do que a mulher, quando as crianças são menores, para seu aprimoramento. Por exemplo, com um nenê pequeno, uma mulher jamais sairia do país por alguns meses para fazer um curso fora, mas os homens saem. Não somente existem diferenças entre homem e mulher, mas existem diferenças para a própria mulher (Sexo feminino, casada, dois filhos, 50 anos).

A maioria ia a todos os congressos e eu só ia quando podia! Quando as minhas crianças eram pequenas, o que favoreceu, viabilizou a vida profissional, foi o bom marido que eu tive (...) mas realmente eu não podia ir a todos os congressos, não publiquei nas melhores revistas, publiquei bastante, mas só no âmbito nacional, sou uma profissional reconhecida pelos meus pares, mas com limitações! Os homens deslancharam mais do que eu!" (...) em termos de carreira, das exigências da carreira, eu realmente fiquei atrás dos meus colegas, não consigo 'correr' junto! (Sexo feminino, casada, três filhos, 54 anos).

É notória a existência de maiores dificuldades para as mulheres, produzidas por determinantes da reprodução humana: gestação, parto e maternidade. Estes fatores se constituem, em muitos casos, em fortes impedimentos para uma trajetória mais linear na carreira profissional.

Na Espanha, as conclusões de um estudo salientam o efeito dos encargos domésticos sobre o desenvolvimento da carreira profissional das mulheres. Trata-se de uma publicação do Sindicato de Sanidad de CC.OO, de Madri, intitulada La Salud de las Mujeres que Trabajan en Hospitales:

No podemos pasar por alto el estamento de médicos, donde la mujer no es mayoritaria ni tampoco alcanza los puestos más altos de la profesión en proporción a su número. A pesar de su larga educación universitaria, las mujeres médicos no son insensibles a la influencia social, a la de los medios de comunicación y a la de su propio grupo de pertenencia, que todavía las persuade de que el matrimonio y la maternidad son estados deseables y de que este rol debe tener preferencia sobre el de su trabajo. Por lo que la mujer en estas condiciones - cuando se casa y tiene niños - se retrasa profesionalmente en comparación con sus colegas hombres y oficialmente poco o nada se hace para compensarle de sus desventajas. (Sindicato..., 1992, p. 180, grifos nossos).

Os 'problemas de saúde, decorrentes do ciclo vital', também foram considerados como obstáculos para a carreira:

A endometriose é uma doença que acontece em mulheres que não têm filhos muito cedo, então eu deixei para ter filhos mais tarde. Quando me casei, já tinha quase 30 anos. Fiquei casada uns três ou quatro anos e a gente resolveu que queria ter 
um filho e aí nada de engravidar. Fui ver e eu tinha endometriose, que é uma coisa que acontece em quem não engravida cedo, é uma doença que acontece em mulheres imunologicamente afetadas, ou seja, sob estresse. Ela é comum em jornalistas, em escritoras, em médicas! Acho que a maior concentração de endometriose é em mulheres que estudam, que vão muito adiante intelectualmente e sofrem e vivem muito sob pressão. Engravidei quatro vezes, só que ocorria morte fetal e eu perdia [chora]. Isso foi um grande desgaste na minha vida, eu tinha feito mestrado e [esse problema] fez com que eu não fosse adiante com minhas coisas, e só de seis anos para cá eu retomei minha vida científica (Sexo feminino, casada, sem filhos, 47 anos).

Somente no discurso feminino foram mencionados obstáculos que se originam da preocupação com a 'preservação da intimidade e da imagem':

No convívio social eu não posso me aproximar muito do professor, entendeu? Viajar... até posso sentar no avião ao lado [deles], mas depois eu não vou dividir o quarto com eles! Na verdade, sempre tenho que ficar sozinha nos congressos e gasto em dobro ou triplo porque não tenho com quem dividir o quarto, e eu não vou jantar com eles, não saio com eles para 'festejar'! Eu não convivo socialmente. Impus a distância, fui sempre muito fria, muito rígida nisso aí (Sexo feminino, casada, sem filhos, 41 anos).

Um aspecto que merece destaque é o peso que os preconceitos sociais podem ter nas opções profissionais e nas atitudes e comportamentos das mulheres. Observou-se que várias médicas manifestaram que consideram fundamental preservar a sua intimidade e cuidar da imagem de seriedade e respeitabilidade que desejam imprimir à sua atuação.

\section{Os obstáculos mencionados pelos homens}

No decorrer das entrevistas, algumas questões relacionadas a obstáculos que incidem na carreira profissional emergiram como predominantes no referencial discursivo masculino. No depoimento de alguns homens, a 'paternidade' foi considerada como obstáculo:

Ter filhos pequenos não tem como não interferir, uma coisa interfere na outra, a minha profissão interfere na maneira como eu convivo com eles, encurtando o tempo de convivência e limitando-o a determinados horários e às vezes nem no fim de semana a convivência é a esperada (Sexo masculino, casado, dois filhos, 42 anos).

Sobre 'os problemas pessoais e a saúde emocional', as falas a seguir são muito elucidativas: 
Obstáculos? A vida pessoal! A vida pessoal em algum momento ameaçou gravemente a minha carreira A história profissional e a história pessoal são separadas, devem ser separadas, mas tem muitos momentos em que elas se misturam. Aconteceu comigo que eu namorava a $\mathrm{X}$, então, logo que terminei a Residência, nós terminamos o namoro e aí nos separamos e eu fiquei muito triste, muito, muito triste, deprimido, muito deprimido! E resolvi que ia parar com tudo e ia viajar um tempo. Aí resolvi passar três meses na Europa sem trabalhar como médico, eu queria trabalhar de garçom. Fiquei muito triste, muito deprimido, mas graças à medicação! Eu fui um suicida praticamente no trabalho, fazia coisas muito autodestrutivas e o que me ajudou muito é que fiz terapia e consegui organizar as coisas e os aspectos positivos. Acho que hoje eu tenho uma carreira de sucesso! (Sexo masculino, solteiro, 35 anos).

Fui fazer a parte médica de uma fábrica, até 83, e fiquei muito nervoso e fui demitido porque estava em crise também e comecei a dar problema para eles; comecei a faltar muito e tive muitos, muitos problemas com a medicação. Mas aí, em seguida, fecharam o departamento médico, foi o ano da recessão econômica. Foi um ano terrível em 83, foi justamente na época em que eu me descredenciei do SUS. Aí começou o meu divórcio, deu um monte de confusão na minha vida! Isso atrapalhou minha vida profissional! Aí me separei, casei de novo e também não deu certo por causa do primeiro e a implicância (Sexo masculino, divorciado, um filho, 53 anos).

Quando vais para o mercado de trabalho, aí muda! Não é tão bonita a vida profissional. Aí entra a nossa verdade como profissional, que não é bonita em certos aspectos, em outros ela é bonita, faz parte da essência dela mesma, que é lidar com pessoas, no sentido humano, isso existe! Mas, do ponto de vista de como tu estás inserido na estrutura, de uma forma tão frágil, exposto dentro de uma estrutura de trabalho, isso é um fator de muito sofrimento. Tu pegas essas pessoas que no corredor elas estão com seu avental, passo firme, mas tu vais sentar numa sala e elas vão dizer que são pessoas que sofrem no trabalho. Eu conheço muitos médicos que são exemplos cabais de sofrimento gerado pelo trabalho. Muitas são pessoas que seguram isso no peito por uma série de coisas até pela luta que as pessoas têm pela carreira, elas lutam muito para se manter naquilo pelo qual tanto já fizeram, mas é gente que sofre muito e às vezes têm muitos casos de depressão, ansiedade, de sofrimento mesmo por essa questão do mercado de trabalho, de se estar dentro de uma estrutura ruim, o que não se tem, por exemplo, na Residência. Claro, tu tens muito estresse, mas a estrutura é outra! Do ponto de vista, digamos assim, de saúde mental, é muito melhor do que vem depois, porque ali tu estás amparado pelos colegas e pelos professores, trabalhando juntos, e depois tu estás mais sozinho, mesmo que tenhas chefe, supervisor. Não me vejo continuando da forma como estou, eu preciso mudar! Tive um problema importante de depressão, fui uma das pessoas que mais sofri porque vim com toda aquela bagagem que te contei 
desde lá no início (formação humanista) e nesta estrutura a gente sofre muito!! Eu entrei em depressão, há uns três anos, e faço tratamento porque não é fácil ficar nessa estrutura e, como estou agora de manhã e de tarde atendendo direto em dois lugares, atendimento de demanda, isso é muito difícil. Não é o que eu queria, não é o que me levou a estudar medicina, é um lado ruim, é um sofrimento para mim, então vou precisar mudar isso, eu quero depois sair disso e entrar mais na vida acadêmica (Sexo masculino, solteiro, 33 anos).

É bastante significativo o sofrimento demonstrado nos depoimentos anteriores. No último relato, os problemas são gerados pelas dificuldades decorrentes das incertezas inerentes ao exercício profissional na medicina. Essa situação vê-se agravada pelas condições objetivas nas quais essa prática se realiza. Embora neste item a ênfase esteja centrada em problemas de saúde emocional, vê-se como, além dos problemas pessoais, emergem também as determinações sociais mais amplas para explicar as condições do meio ambiente de trabalho e a qualidade de vida.

Ao tratar do tema dos obstáculos para a profissão, chama a atenção que vários médicos e médicas fizeram referência a alguns problemas com a sua saúde, como sendo, em algumas ocasiões, empecilhos para a carreira. É interessante observar que, ao se compararem ambos os gêneros, enquanto as mulheres abordaram mais os aspectos físicos de alguma doença, os homens se referiram mais a questões emocionais, mencionando o impacto decorrente do rompimento de alguma relação conjugal, por exemplo.

Intercorrências da vida pessoal emocional parecem afetar mais os homens do que as mulheres, mas não é possível fundamentar esta afirmação a partir da amostra deste estudo, pois é necessário um maior aprofundamento sobre o impacto das separações e divórcios comparativamente na vida de homens e mulheres, e isto se afasta dos objetivos deste trabalho. No entanto, cabe mencionar uma pesquisa que Filardo realizou no Uruguai, pois é uma referência comprobatória dessa questão. A autora afirma que, nos homens, o peso do divórcio, da viuvez e do fato de permanecer solteiro sempre é relativamente maior do que nas mulheres (Filardo, 2000, p. 50).

\section{Os obstáculos no discurso de ambos os gêneros}

Antes de abordar a temática dos obstáculos, é necessário traçar um perfil dos profissionais da área médica que atuam no HCPA, tomando como base os dados coletados na pesquisa de campo. No Gráfico 1, é possível observar diferenças sobre o número de atividades dos médicos e médicas (em locais diferentes, como por exemplo trabalho em hospitais, consultórios particulares, laboratórios, postos de saúde etc.): 
Gráfico 1

Número de atividades segundo gênero

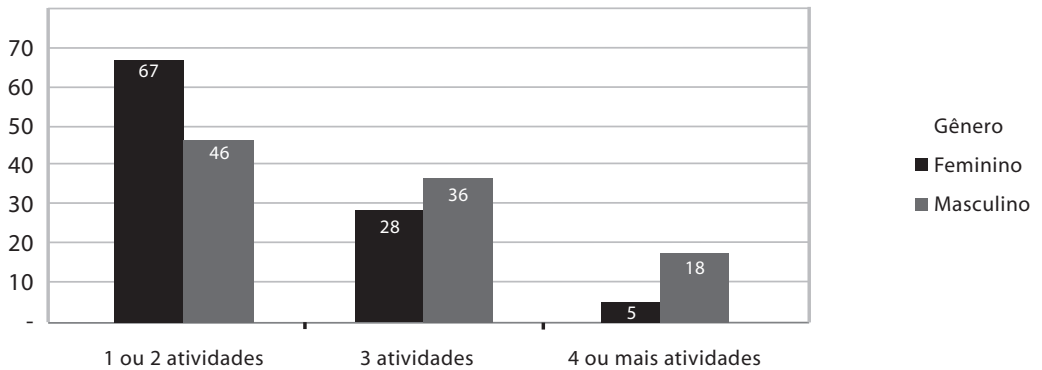

Fonte: A autora.

Nota: Número de atividades em locais de trabalho diferentes; dados em percentagens.

Por outro lado, observa-se nos homens uma tendência maior à inserção no mercado empresarial privado da área médica do que nas mulheres:

Tabela 2

\begin{tabular}{ll|ccc|}
\hline \multicolumn{2}{l}{ Vínculo de trabalho com empresa privada, segundo gênero } \\
\hline & & \multicolumn{3}{c}{ Gênero } \\
\cline { 3 - 5 } & & Mulheres & Homens & Total \\
\hline \multirow{2}{*}{ Empresa privada } & Sim & $29(29,3 \%)$ & $44(43,1 \%)$ & $73(36,3 \%)$ \\
& Não & $70(70,7 \%)$ & $58(56,9 \%)$ & $128(63,7 \%)$ \\
& Total & $99(100 \%)$ & $102(100,0 \%)$ & $201(100 \%)$
\end{tabular}

Fonte: A autora.

Como nos homens os encargos familiares geralmente são menores do que no caso das mulheres, eles podem, de modo geral, dedicar maior tempo a sua carreira profissional. Constatou-se que os médicos têm melhores possibilidades de diversificar suas atividades. Isto incide na ampliação dos seus contatos no mundo do trabalho, o que possivelmente redunde em melhores oportunidades de inserção ocupacional e renda. 10

Analisando-se o que é comum a ambos os gêneros, ao tratar a questão dos obstáculos na vida profissional, percebe-se que 'tempo'11 e 'dinheiro' tornamse os principais entraves à carreira. A 'falta de tempo' é sentida no campo profissional e no doméstico. A questão dos recursos financeiros é importante, pois, em geral, a profissão médica exige investimentos constantes em termos 
de equipamentos, material e viagens para participar de eventos a fim de se manter atualizado em relação aos avanços científicos e tecnológicos.

Em relação à 'falta de tempo e excesso de trabalho', como obstáculos, os seguintes depoimentos são semelhantes:

Eu estava trabalhando feito louco e aí fiz os cálculos: eu tinha dois empregos, tinha o hospital de Clínicas e tinha uma clínica geriátrica, mais o consultório (Sexo masculino, divorciado e casado novamente, um filho, 53 anos).

Foi na época que eu tinha uma série de coisas, logo que eu terminei o mestrado, foi em 96, e com o mestrado não ficava muito tempo vago devido a eu ter trabalhado de uma maneira brutal (Sexo masculino, casado, um filho, 38 anos).

O grau de solicitação é muito grande, a vida não existe, tu chegas em casa oito e meia, nove horas, e daí vem a questão 'tema' e quando tu paras, tu vais para a internet, porque tu tens que estudar (Sexo feminino, casada, um filho, 41 anos).

Sobre as dificuldades financeiras, assim se manifestaram alguns profissionais:

Acho que uns $30 \%$ dos residentes acabam fazendo algumas atividades fora, para complementar a bolsa porque é muito baixa! E o que a gente gasta! Eu moro sozinho e gasto com luz e outras coisas, e tenho um filho que mora com a mãe e pago o plano de saúde dele e eu gostaria de não precisar fazer plantão, mas a gente acaba precisando (Sexo masculino, solteiro, um filho, 29 anos).

Mal-remunerados, acabamos tendo que fazer muito mais coisas do que gostaríamos para manter essa condição. De repente, mais no final da carreira, a pressão econômica já não é mais tão grande, os filhos já não dão mais tanta despesa, os compromissos não são mais tantos (Sexo masculino, casado, dois filhos, 42 anos).

Acho que se eu tivesse melhores condições financeiras, teria deslanchado mais! Mas considerando justamente o meu nível socioeconômico e social e a minha trajetória, foi uma grande, uma grande evolução! (Sexo feminino, casada, três filhos, 54 anos).

Cabe registrar também que alguns profissionais do HCPA fizeram referência a problemas físicos ou emocionais, cansaço e estresse na sua menor produtividade científica e disposição para participar dos eventos. Consultando os resultados da pesquisa sobre os médicos no Brasil, coordenada por Maria Helena Machado, 12 verifica-se que existe uma proporção muito elevada de profissionais que apresentam problemas de pressão e desgaste, pois, segundo a autora, em 14 especialidades, numa percentagem acima de $90 \%$, eles afirmaram sentir esse problema. A autora apresenta detalhes sobre quais 
foram os principais motivos alegados para o desgaste profissional na área médica: excesso de trabalho, jornada de trabalho prolongada, múltiplo emprego $(27 \%)$, baixa remuneração $(17 \%)$, más condições de trabalho $(16 \%)$; área de atuação/especialidade ( $9 \%$ ); excesso de responsabilidade, relação de vida e morte com os pacientes (12\%) (Machado, 1997, p. 184).13

É interessante destacar o perfil elaborado por Machado sobre os profissionais do país, de ambos os gêneros, que apresentam maiores índices de estresse: estão em início de carreira, trabalham em quatro ou mais atividades, trabalham como plantonistas, principalmente em setores de emergência e pronto-socorro, em hospitais públicos ou em serviços de apoio terapêuticodiagnóstico em empresas privadas, são especialistas em doenças crônicodegenerativas, cirurgiões, médicos residentes que atuam em áreas cirúrgicas, obstetras, têm baixa remuneração, trabalham em municípios diferentes daqueles em que residem ou exercem suas atividades em condições precárias (Machado, 1997, p. 186). Os dados da pesquisa indicam que mais da metade dos médicos entrevistados mencionaram que as condições de trabalho interferem negativamente em sua prática profissional. A insatisfação é consequência do: “a) excesso de atividades; b) más condições de trabalho; c) salários baixos. A autonomia profissional (seja ela técnica ou econômica) torna-se fragilizada e difícil de ser sustentada" (Machado, 1996, p. 181).

Considerando o fator geracional, na pesquisa realizada no HCPA, foram analisados os fatores que interferem nas atividades científicas. Comparando-se os profissionais mais jovens, os quais constituem a subamostra dos residentes desta pesquisa, obteve-se o seguinte resultado:

Gráfico 2

Fatores que interferem nas atividades científicas, segundo a idade

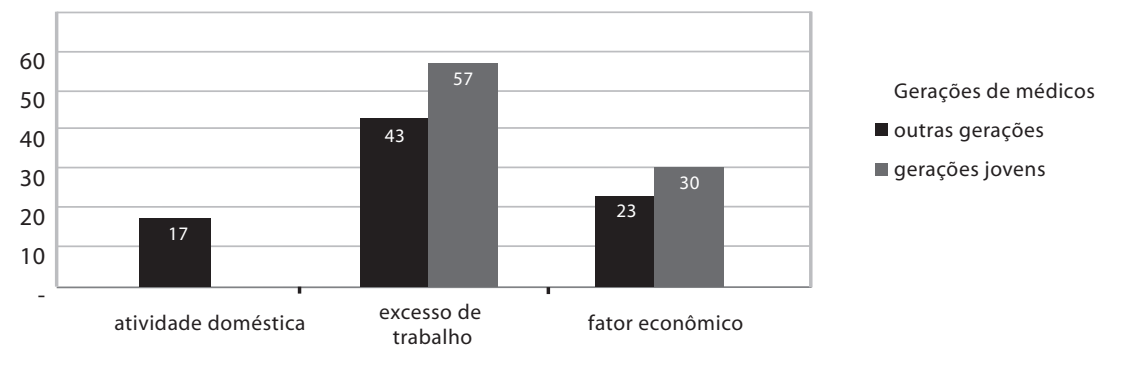

O excesso de trabalho é a categoria que teve percentagens mais elevadas, sendo maior entre os mais jovens (57\%) do que entre as outras gerações de 
médicos. ${ }^{14}$ Comparando estes resultados com os dados nacionais, $91 \%$ dos médicos residentes sentem desgaste profissional e estresse provocado pelas longas e cansativas jornadas de trabalho (Machado, 1997, p. 74). Machado apresenta uma tabela dos médicos distribuídos por desgaste profissional segundo faixa etária, a qual indica que, à medida que aumenta a faixa etária, o sentimento de desgaste tende a baixar (a partir dos 50 anos, a percentagem encontra-se entre $48 \%$ e $70 \%$ ). O fator econômico parece ser um obstáculo maior entre os mais jovens, e as atividades domésticas foram referidas somente pelos profissionais de mais idade, pois os encargos com família e filhos parecem interferir mais que entre os mais jovens, a maioria ainda solteira ou sem filhos.

\section{Vantagens comparativas das mulheres}

Embora ainda persistam discriminações de gênero, as habilidades femininas e masculinas na medicina hoje são conceituadas de forma mais equitativa. Cappellin (1996), num estudo sobre ações afirmativas, faz referência às 'políticas de valorização da diferença feminina', questão da maior importância atualmente como estratégia de superação dos históricos preconceitos e discriminações em relação ao trabalho das mulheres. Esta temática foi identificada no discurso de ambos os gêneros, que enfatizaram vários elementos positivos no estilo feminino de exercer a medicina.

Alguns estudos mais atuais fazem referência às 'vantagens comparativas' das mulheres pelo fato de ser do sexo feminino. Parte-se do princípio de que suas características e peculiaridades deveriam deixar de ser concebidas como desvantagem e passar a ser consideradas como algo positivo. Assim, nos últimos anos, se observa uma maior valorização do 'estilo feminino' de trabalho no campo profissional.

Não se trata aqui de reproduzir estereótipos de comportamentos femininos ou masculinos, buscando identificar 'essências naturais' dicotômicas em cada um dos dois gêneros, mas existem algumas peculiaridades próprias a cada gênero produzidas por uma socialização diferenciada, independentemente do que o indivíduo concreto, homem ou mulher, possa manifestar nos seus valores e comportamentos.

A feminização da medicina parece estar transformando o estilo da prática médica. A inserção de um número maior de mulheres na profissão tem tornado as relações entre os profissionais mais cooperativas, o trabalho em equipe tende a predominar, e nas relações médico-paciente observa-se uma atitude de maior diálogo e interação.

Em muitas falas, principalmente femininas, foi enfatizada especialmente a questão da atitude 'maternal' de muitas mulheres, o que configuraria um 
determinado estilo feminino de exercer a medicina: “Acho que há um outro olhar, acho que a atividade com os alunos é diferente também, tu percebes o aluno que não está bem emocionalmente, tu consegues puxar, há um relacionamento" (Sexo feminino, casada, um filho, 41 anos). Outra médica reforça esta visão: "Eu acho que pela própria inerência da mulher à coisa da maternidade, de ser mais maleável, de não ser tão impositiva, de ser mais tranquila, de conseguir ouvir mais as pessoas. Acho que a qualidade do atendimento melhorou muito!" (Sexo feminino, casada, grávida, 37 anos).

É significativo que em algumas narrativas masculinas também apareça a mesma referência às características maternais das mulheres ao exercer a profissão médica: "Quando as mulheres vão se tornando um pouco mais antigas na sua especialidade, elas tendem a ter um jeito mais de mãe" (Sexo masculino, casado, um filho, 38 anos). Outro médico considera que 'por serem mulheres', elas tratam os pacientes nas consultas de forma diferente: demoram mais, conversam mais e veem mais o lado psicológico do que os homens. E acrescenta: “A mulher tem um espírito mais protetor e acaba tendo mais uma atitude de cobrança com os pacientes do que os homens, parece mais um estilo maternal. O homem fala, mas não dá uma ênfase no relacionamento tanto quanto as mulheres"'(Sexo masculino, solteiro, 25 anos).

Os gêneros apresentam características 'diferentes' e parecem existir determinados atributos ou disposições, socialmente adquiridos (habitus, na linguagem bourdiana), específicos a cada um, construídos no processo educacional. É importante reconhecer, no entanto, que nem todas as mulheres são por 'natureza' maternais e que muitos homens também estabelecem uma interação dialógica com seus pacientes e colegas de trabalho, exercendo sua profissão com competência e dedicação.

\section{Considerações finais}

A dominação masculina atua de forma androcêntrica na nossa sociedade, gerando diversas discriminações e preconceitos. Existem habitus específicos para homens e mulheres, construídos e reproduzidos pelo processo educacional. Desde a infância, ambos os gêneros são submetidos a valores, práticas e expectativas diferenciadas sobre o desempenho esperado dos papéis masculinos e femininos.

As discriminações de gênero (e as decorrentes da idade) geram diversos estereótipos e rotulações, interferindo no livre desenvolvimento das potencialidades dos diversos agentes. Neste trabalho, foi possível observar, tomando como base os relatos dos entrevistados e dados do levantamento quantitativo, algumas diferenças de gênero significativas em relação à manifestação de discriminações no ambiente de trabalho. 
Certos aspectos são mais enfatizados na cosmologia masculina e outros na feminina, o que indica que, mesmo vivenciando uma realidade ocupacional semelhante, suas pautas de socialização moldam representações simbólicas diferentes.

Os médicos de ambos os gêneros vivenciam, no exercício profissional, um aspecto muito semelhante: exercem suas atividades em longas jornadas de trabalho. Observou-se, no entanto, uma diferenciação no desempenho do trabalho: os homens tendem a se envolver mais com o múltiplo emprego (ocupação simultâneas em locais diferentes) enquanto a maioria das mulheres concentra-se principalmente em dois locais de trabalho: hospital e consultório particular.

Foram analisados, em detalhe, os fatores negativos e positivos que se constituem em estímulos ou obstáculos à melhor estruturação da carreira profissional na medicina, assinalando as intercorrências mais frequentes.

Médicos e médicas vivenciam um cotidiano permeado de dificuldades para conciliarem a vida profissional com a vida doméstica e mencionam obstáculos decorrentes da falta de tempo e do excesso de trabalho. Também foram mencionados problemas financeiros (lembre-se que a amostra deste estudo é constituída de funcionários de um hospital público universitário, onde as remunerações são menores).

A interferência da vida familiar na profissional é maior entre as mulheres do que entre os homens, o que pode explicar que elas reduzam suas atividades principalmente a duas, como mencionado anteriormente (inversamente, os homens demonstraram maior preocupação com a interferência da sua profissão na vida familiar). Foram mais frequentes nelas a referência à sobrecarga provocada pelas responsabilidades domésticas. No entanto, é importante evitar as generalizações apressadas, pois os homens casados e com filhos, evidentemente, apresentam uma interferência maior do que as mulheres solteiras ou divorciadas.

A articulação do campo profissional com o doméstico e uma maior equidade de gênero relativa às condições de vida e trabalho passam necessariamente pela questão de uma divisão sexual do trabalho mais igualitária e maiores investimentos em políticas sociais e infraestrutura de apoio à estruturação familiar. Estas ações públicas deveriam ser direcionadas a facilitar as tarefas domésticas e o cuidado dos filhos, idosos e doentes, atividades essencialmente femininas, na maioria dos lares do país.

Quanto à questão dos obstáculos decorrentes de problemas da saúde mencionados pelos médicos e médicas que atuam no HCPA, chamou a atenção que nas mulheres os relatos centraram-se mais nos aspectos físicos enquanto os homens enfatizaram mais os aspectos emocionais.

Em relação aos fatores de estímulo para a carreira, os dados coletados indicam que as mulheres parecem voltar-se mais para elementos da vida privada, 
considerando a importância do incentivo da família, do apoio do cônjuge, do tipo de personalidade e dos elogios, enquanto no referencial dos homens são reforçados mais os elementos externos (esfera pública), tais como encaminhamento de pacientes, existência de familiares médicos e consciência social e política.

Considerando o que é comum no discurso de ambos os gêneros, sobre os fatores de estímulo, foram enfatizados os seguintes aspectos: a importância de um 'modelo' de profissional competente e ético na sua formação, o incentivo de um meio acadêmico qualificado, relações humanas positivas no ambiente de trabalho e a questão do apoio e oportunidades propiciadas pelas instituições de pesquisa.

Existem indícios da emergência de um novo estilo de liderança mais participativa e dialógica, no qual as mulheres contribuem com formas peculiares de exercício profissional. A feminização da profissão médica é uma realidade, e as mulheres buscam conquistar maior reconhecimento e valorização do seu trabalho na esfera profissional e doméstica, em igualdade de condições em relação aos homens.

Resta dizer ainda que as denominadas 'vantagens comparativas' das mulheres sinalizam a possibilidade de maior valorização das capacidades femininas. A equidade de gênero é algo socialmente construído, através de novos habitus e práticas, e implica na superação de hierarquias, valores e comportamentos discriminatórios no âmbito privado e no campo profissional, extensivo também à problemática das gerações.

\section{Notas}

1 Professora adjunta da Universidade Federal do Rio Grande do Sul (UFRGS), Porto Alegre, Rio Grande do Sul, Brasil. Doutora em Sociologia pela Universidade Federal do Rio Grande do Sul. <barquis@orion.ufrgs.br>

Correspondência: Rua Garibaldi, 1.071, apto. 202, Porto Alegre, Rio Grande do Sul, Brasil, CEP 90035-052.

2 Estudos sobre carreira profissional fazem parte da área do conhecimento denominada Sociologia das Profissões. No seu interior é possível identificar subáreas temáticas, entre as quais encontram-se os estudos sobre a divisão sexual do trabalho e as relações de gênero. Este campo pode ser considerado constitutivo, por sua vez, da Sociologia do Trabalho. Uma obra pioneira importante da Sociologia das Profissões é a coordenada por Maria H. Machado, sob o título: Profissões de saúde: uma abordagem sociológica (1995). É importante consultar também a obra de Bonelli e Donatoni (1996), especialistas na área. 
3 O número de mulheres que ocupam cargos de chefia ou direção nos diversos setores da área médica do HCPA é muito baixo: de 43 especialidades existentes no hospital, somente seis (14\%) são ocupadas por mulheres.

$4 \mathrm{Na}$ Famed, exercem suas atividades docentes médicos que são funcionários públicos federais, com regime de trabalho estatutário e com estabilidade no emprego. Os médicos e médicas que estão na categoria de contratados são celetistas.

5 Fazem parte da amostra quantitativa, intencional, 201 profissionais da medicina, e da amostra qualitativa, 27. Os principais instrumentos de coleta de dados empíricos utilizados foram o questionário padronizado e a entrevista semiestruturada, através de roteiro de entrevista. Para o processamento dos dados quantitativos foi empregado o programa SPSS (Statistical Package for the Social Sciences). Os dados qualitativos foram processados e analisados através do programa NVivo/CAQDAS (Computer-Aided Qualitative Data Analysis Software).

6 Outras alternativas de resposta na pergunta do questionário sobre tipos de discriminação: por raça, religião, aparência física, deficiência física e opção sexual. Todas estas categorias tiveram percentagens muito baixas.

7 Sobre os conceitos de habitus e 'campo' de Bourdieu, consultar um estudo que publiquei anteriormente, denominado (Des)encontros de Pierre Bourdieu com o marxismo: relações objetivas, representações simbólicas e ação. O habitus pode ser definido como 'sistemas de percepção, apreciação e ação'. O 'campo' é um sistema de relações objetivas que define e aciona uma forma específica de interesse (Bourdieu apud Santos, 2003, p. 125-6).

8 É necessário evitar as generalizações apressadas, pois a questão da idade requer um estudo mais aprofundado para avaliar a intercorrência desse fator na competência e qualificação, assim como na imagem do profissional, não sendo este o foco central da pesquisa que resultou neste artigo.

${ }_{9}$ Sobre esta questão, um estudo especializado é o de Daniel Goleman (1999).

10 Dados, em nível nacional, da pesquisa coordenada por Machado mostram que as mulheres na profissão médica têm renda mensal menor do que os homens: $66,2 \%$ das mulheres em todo o país ganham até 2 mil dólares, enquanto apenas 34\% dos homens se encontram nessa faixa. A distribuição por sexo nas faixas superiores indica que $20,7 \%$ dos homens ganham entre 4.001 e 8 mil dólares, enquanto as mulheres representam somente 5,2\% nessa faixa de renda (Machado, 1997, p. 154).

11 No Uruguai, os estudos de Batthyány (2000) têm focalizado, nos últimos anos, a temática do tempo de trabalho das mulheres, tomando como base as pesquisas realizadas por Aguirre (2000) e Duran (2000).

12 A pesquisa foi publicada sob o título "Perfil dos Médicos no Brasil" e teve o patrocínio da Fundação Oswaldo Cruz e do Conselho Federal de Medicina. A amostra selecionada para a pesquisa foi de 14.383 médicos e médicas de capitais e localidades do interior de todo o país.

13 Entre as causa principais de desgaste profissional, Machado lista os fatores em ordem decrescente de importância: excesso de trabalho/multiemprego, baixa remuneração, más condições de trabalho, responsabilidade com a 'vida', área de atuação/especialidade, relação médico-paciente, conflito/cobrança da população e perda de autonomia (Machado, 1997, p. 173). 
14 Foram considerados como geração mais jovem a população dos médicos residentes que atuam no HCPA, aproximadamente 300, e comparados a médicos e médicas de outras faixas etárias a partir dos 40 anos. A soma das percentagens não corresponde a $100 \%$ porque foram omitidas duas categorias de respostas que tiveram valores muito baixos: 'falta de apoio de instituições de pesquisa' e 'somente responde sim'.

\section{Referências}

AGUIRRE, Rosario. Trabajo y ciudadanía de las mujeres en Uruguay. Revista de Ciências Sociales, Montevideo, n. 18, p. 71-82, sep. 2000.

BATTHYÁNY, Karina. Estado, família y políticas sociales: quien se hace cargo de los cuidados y las responsabilidades familiares? Revista de Ciências Sociales, Montevideo, n. 18, p. $71-82$, sep. 2000 .

BARBOSA, Maria Lígia de Oliveira. A sociologia das profissões: em torno da legitimidade de um objeto. BIB: Boletim Informativo e Bibliográfico de Ciências Sociais, Rio de Janeiro, n. 36, p. 3-32, set. 1993.

BONELLI, Maria da Gloria; DONATONI, Silvana. Os estudos sobre profissões nas ciências sociais brasileiras. BIB: Boletim Informativo e Bibliográfico de Ciências Sociais, Rio de Janeiro, n. 41, p. 109-142, 1. sem. 1996.

BOURDIEU, Pierre. A economia das trocas linguísticas. In: ORTIZ, Renato (Org.). Pierre Bourdieu: sociologia. São Paulo: Ática, 1983. p. 156-183.

A dominação masculina. Rio de Janeiro: Bertrand Brasil,1999.

Os usos sociais da ciência: por uma sociologia clínica do campo científico. São Paulo: Editora Unesp, 2004.

CAPPELLIN, Paola. Ações afirmativas: uma estratégia para corrigir as desigualdades entre homens e mulheres. In: LIGOCKI, Malô S. L.; LIBARDONI, Marlene (Orgs.). Discriminação positiva - ações afirmativas: em busca da igualdade. São Paulo: CFEMEA/ Elas, 1996. p. 13-31.

DURAN, Maria-Angeles. Uso del tiempo y trabajo no remunerado. Revista de Ciências Sociales, Montevideo, n. 18, p. 56-70, sep. 2000.

FILARDO, Verónica. Género y jubilación: el caso de la profesión médica. Revista de Ciências Sociales, Montevideo, n. 18, p. 4155, sep. 2000.

FOUCAULT, Michel. Vigiar e punir. Petrópolis: Vozes, 1977.

FUNDAÇÃO PERSEU ABRAMO. Núcleo de Opinião Pública. A mulher brasileira nos espaços público e privado. São Paulo, 2001. Disponível em: <www.fpabramo.org.br/nop/ nop.htm>. Acesso em: 23 set. 2008.

GOLEMAN, Daniel. Trabalhando com a inteligência emocional. Rio de Janeiro: Objetiva, 1999.

IZQUIERDO, María Jesús. El malestar en la desigualdad. Madrid: Cátedra, 1998.

MACHADO, Maria Helena. (Org.) Profissões de saúde: uma abordagem sociológica. Rio de Janeiro: Editora Fiocruz, 1995.

Os médicos e sua prática profissional: as metamorfoses de uma profissão. Tese (Doutorado em Sociologia) - Rio de Janeiro: Instituto Universitário de Pesquisas do Rio de Janeiro, Iuperj, 1996.

(Coord.). Os médicos no Brasil: um retrato da realidade. Rio de Janeiro: editora Fiocruz, 1997. 
PUPPIN, Andréa. Mulheres em cargos de comando. In: BRUSCHINI, Cristina; SORJ, Bila (Orgs.). Novos olhares: mulheres e relações de gênero no Brasil. São Paulo: Marco Zero: Fundação Carlos Chagas, 1994. p. 13-35.

SAFFIOTI, Heleieth. Rearticulando gênero e classe social. In: COSTA, Albertina de O.; BRUSCHINI, Cristina (Orgs.). Uma questão de gênero. Rio de Janeiro: Rosa dos Tempos; São Paulo: Fundação Carlos Chagas, 1992. p. 183-215.

. Quem tem medo dos esquemas patriarcais de pensamento?. Crítica Marxista, São Paulo, n. 11, p. 71-75, out. 2000.
SANTOS, Tania Steren dos. (Des)encontros de Pierre Bourdieu com o marxismo: relações objetivas, representações simbólicas e ação. Humanas, Porto Alegre, v. 25, n. 1/2, p. 115-149, 2002-3.

SINDICATO DE SANIDAD DE CC.OO. La salud de las mujeres que trabajan en hospitales. In: BARAÑANO, Margarita (Org.). Mujer, trabajo, salud. Madrid: Trotta, 1992. p. 13-43. Colección Estructuras y Procesos.

VALLE, Patrícia Barroso do. Inteligência emocional no trabalho: um estudo exploratório. Dissertação (Mestrado profissionalizante em Administração) - Rio de Janeiro: Programa de Pós-Graduação em Administração e Economia, Ibmec, 2006.

Recebido em 06/05/2009

Aprovado em 10/11/2009 